\title{
Torque Ripple Suppression for IPMSM using FEA- based Model Predictive Direct Torque Control
}

\author{
Ahmed Nasr ${ }^{1}$, Chunyang $\mathrm{Gu}^{1,3}$, Weiduo Zhao ${ }^{1}$, Serhiy Bozhko², Chris Gerada ${ }^{2}$ \\ ${ }^{1}$ Key Laboratory of More Electric Aircraft Technology of Zhejiang Province, University of Nottingham Ningbo China \\ Ningbo, China (ORCID: 0000-0002-7700-278X; 0000-0003-1283-1701; 0000-0002-7098-2957) \\ ${ }^{2}$ Deptartment of Electrical and Electronic Engineering, University of Nottingham, Nottingham, UK \\ (ORCID: 0000-0002-0508-7198; 0000-0003-4707-4480) \\ ${ }^{3}$ Key Laboratory of Virtual Manufacturing Technology, Fujian University, Fuzhou, China
}

\begin{abstract}
The interest in model predictive direct torque control (MP-DTC) for high-performance dynamic control of electric drives has been growing. Unlike the conventional direct torque control (DTC), MP-DTC can achieve optimal voltage selection by predicting the control variables evaluations using a machine model. However, the model-machine mismatch can degrade the control performance significantly, especially for the interior permanent magnet synchronous machine (IPMSM) because of its highly nonlinear characteristics. Therefore, this paper describes an investigation of the MP-DTC algorithm that exploits the advantages of a finite element analysis (FEA) based model in representing the behavior of the IPMSM precisely, including the magnetic saturation and spatial harmonics effects, to suppress the torque pulsations and eliminate the steady-state torque error. Moreover, this approach optimizes the duty ratio simultaneously with the voltage vector selection to guarantee further torque ripple reduction under steady-state operation, especially at low speeds. Simulation results of an $80-\mathrm{kW}$ IPMSM drive are presented to validate the model and the proposed control method.
\end{abstract}

Keywords-FEA-based model, permanent magnet synchronous motor (PMSM), model predictive control (MPC), direct torque control (DTC), torque ripple.

\section{INTRODUCTION}

Due to the rotor saliency, the interior permanent magnet synchronous machine (IPMSM) produces a reluctance torque in addition to the torque component produced by the magnets, exhibiting higher torque density, higher efficiency, and wide constant power range compared with the surface-mount PMSM (SPMSM) [1]. Therefore, it is more attractive for many applications, such as electric vehicles, aerospace, marine traction system [2]. On the other hand, that saliency introduces a higher torque ripple due to the intrinsic variation of the magnetic energy with the rotor position, and leads to the nonlinear torque-current characteristics that make the design of a highperformance control system more challenging [3]. The torque ripple is a critical issue for these applications as it can produce mechanical vibration and acoustic noise [4].

As a high-performance control scheme that can achieve a sufficiently high bandwidth, direct torque control (DTC) is utilized in $[5,6]$ to reduce the torque pulsations of PMSM. This method directly controls both the torque and the stator flux amplitude using a predefined switching table, from which

This research was supported by the National Key Research Program of China under Grant 2017YFB0102304, Ningbo Science \& Technology Beauro under Grant 2018B10002, the Fujian University Key Laboratory of Virtual Manufacturing Technology, and in part by the Natural Science Foundation of Zhejiang Province under Grant LQ19E070002. a voltage vector is selected based on the error between the reference and estimated values [7]. The torque estimator considers the ripple as a known external load that is predetermined using either an analytical model [4, 8] or finite element analysis (FEA) based model [6]. Although DTC can effectively mitigate the cogging torque, it contributes to the torque ripple because the switching table cannot ensure optimal voltage vector selection. Also, that vector is employed for the whole control cycle, which in many cases is undesired [9]. Hence, the model predictive DTC (MP-DTC) [10-14] and duty regulation-based DTC (DDTC) $[15,16]$ are introduced as alternatives.

Unlike the conventional DTC, MP-DTC utilizes a system model to predict the future states, i.e., torque and stator flux amplitude, under the different inverter's voltage vectors. Then, a cost function is employed to select the voltage vector that achieves the optimal solution [17]. As a result, MP-DTC can achieve better torque control performance than the conventional DTC [9]. To guarantee further reduction of torque ripple, the duty ratio regulation concept is applied with MP-DTC in [18] and [11] to insert a zero voltage vector next to an active voltage vector during each control period. However, the existing MP-DTC methods focus on reducing the torque ripple due to the control algorithm, and hence neglect the magnetic saturation and spatial harmonics effects of the machine in the prediction model. During practical implementation, this leads to machine-model mismatch that can degrade the control performance significantly and cause high steady-state error. Thus, accurate modeling of the machine is an essential requirement for MP-DTC.

With the high-accuracy offered by the FEA in evaluating the machine parameters, the modeling-accuracy can be ensured [19]. A high-accuracy and computationally efficient IPMSM model is presented in [20]. This model extracts the flux linkage data from FEA results at different currents and rotor positions to consider both the magnetic saturation, and the cogging torque. Therefore, this paper uses that model with an advanced MP-DTC approach that optimizes the voltage vector selection simultaneously with its working duration to minimize the torque pulsations and steady-state torque error of an $80 \mathrm{~kW}$ IPMSM drive system. The feasibility and effectiveness of the proposed method are confirmed by a comparison with the conventional MP-DTC techniques.

The rest of this work is organized as follows. Section II introduces the mathematical models of IPMSM and converter. The basic principle of the proposed control approach is described in Section III. In Section IV, the FEA-based model of an IPMSM prototype is presented. Section V shows the simulation results and verifications of the proposed method. Finally, conclusions are drawn in Section VI. 


\section{MODEL OF IPMSM AND INVERTER}

The electrical dynamic behavior of the IPMSM can be represented in the rotor reference frame $(\mathrm{dq})$ using the flux linkage-based model as [19]

$$
\begin{gathered}
\left\{\begin{array}{c}
v_{d}=i_{d} R_{s}+\frac{d \psi_{d}}{d t}-\omega_{e} \psi_{q} \\
v_{q}=i_{q} R_{s}+\frac{d \psi_{q}}{d t}+\omega_{e} \psi_{d}
\end{array}\right. \\
\left\{\begin{array}{c}
\psi_{d}=L_{d} i_{d}+\psi_{p m} \\
\psi_{q}=L_{q} i_{q}
\end{array}\right. \\
T_{e}=\frac{3 p}{2}\left(\psi_{d} i_{q}-\psi_{q} i_{d}\right)+T_{c o g}
\end{gathered}
$$

where $V_{d}, V_{q}, i_{d}, i_{q}, \psi_{d}, \psi_{q}, L_{d}, L_{q}$ are the dq-components of the stator voltage, current, flux linkage, and inductance, respectively; $\omega_{e}$ is the electrical angular speed of the rotor; $T_{e}$ is the electromagnetic torque; $T_{c o g}$ is the cogging torque; $\psi_{p m}$ is the permanent magnet flux; $p$ is the number of pole pairs; $R_{S}$ is the stator winding resistance.

The two-level voltage source inverter (2L-VSI) provides eight voltage vectors to feed the IPMSM [21]. These voltage vectors can be expressed, using the switching states of the inverter's legs $\left(S_{1}, S_{2}, S_{3} \in\{0,1\}\right)$, as [14]

$$
V_{i}=\frac{2 V_{d c}}{3}\left(S_{1}+a S_{2}+a^{2} S_{3}\right)
$$

where $i \in\{0,1 . ., 7\}$ is the voltage vector index; $V_{d c}$ is the DClink voltage, and $a=e^{j 2 \pi / 3}$.

\section{PROPOSED MP-DTC METHOD FOR IPMSM}

Fig. 1 shows the overall control diagram of the proposed method. First, the torque $\left(T_{e}^{k}\right)$ and the stator flux amplitude $\left(\psi_{s}^{k}\right)$ need to be estimated from the measured current signals. Then, a prediction model is used to determine the future values $\left(T_{e}^{k+1}\right.$ and $\left.\psi_{s}^{k+1}\right)$ under each voltage vector. Finally, a cost function evaluates these predictions to select the optimal voltage vector and its duty ratio $\left(V_{x}\right.$ and $\left.D_{x}\right)$ that force the torque and the stator flux to follow their references $\left(T_{e}^{\text {ref }}\right.$ and $\left.\psi_{s}^{\text {ref }}\right)$. A detailed description of this diagram is presented next.

\section{A. Flux and Torque Estimation}

The stator flux $\psi_{s}^{k}$ can be estimated based on either the voltage or the current equations, i.e., (1) or (2), respectively. The former is preferred because of its robustness against inductance variations with the magnetic saturation [15]. For precise torque estimation, the torque maps versus the dq-currents at different rotor positions are determined by the FEA, as will be seen in Section IV.

\section{B. Prediction model}

The future values of stator flux amplitude $\psi_{s}^{k+1}$ can be obtained by discretizing (1) using forward Euler approximation as follows [14]:

$$
\left\{\begin{array}{c}
\psi_{d}^{k+1}=\psi_{d}^{k}+T_{s}\left(v_{d}^{k}-i_{d}^{k} R_{s}+\omega_{e}^{k} \psi_{q}^{k}\right) \\
\psi_{q}^{k+1}=\psi_{q}^{k}+T_{s}\left(v_{q}^{k}-i_{q}^{k} R_{s}-\omega_{e}^{k} \psi_{d}^{k}\right) \\
\psi_{s}^{k+1}=\sqrt{\left(\psi_{d}^{k+1}\right)^{2}+\left(\psi_{q}^{k+1}\right)^{2}}
\end{array}\right.
$$

where $k$ is the sampling instant, and $T_{S}$ is the sampling period.

In the conventional methods, according dq-flux linkages $\psi_{d}^{k+1}$ and $\psi_{q}^{k+1}$, constant parameters (i.e., $\psi_{p m}, L_{d}$ and $L_{q}$ ) are employed to determine the current as

$$
\left\{\begin{array}{c}
i_{d}^{k+1}=\left(\psi_{d}^{k+1}-\psi_{p m}\right) / L_{d} \\
i_{q}^{k+1}=\psi_{q}^{k+1} / L_{d}
\end{array}\right.
$$

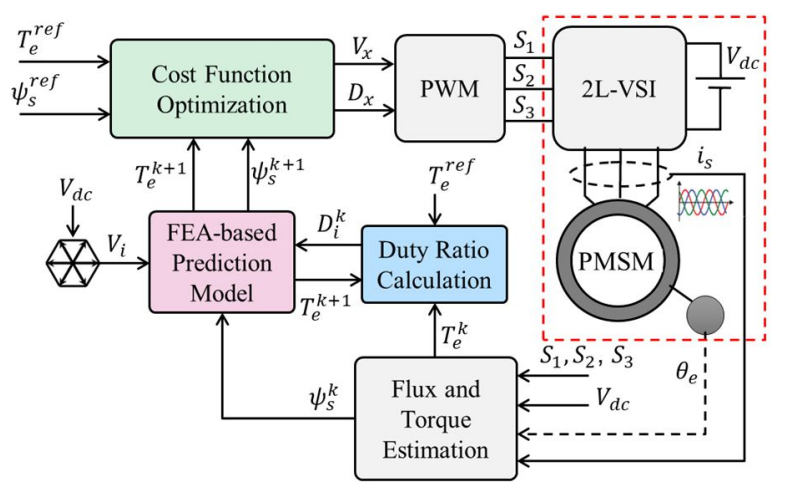

Fig. 1. Block diagram of the proposed MP-DTC method

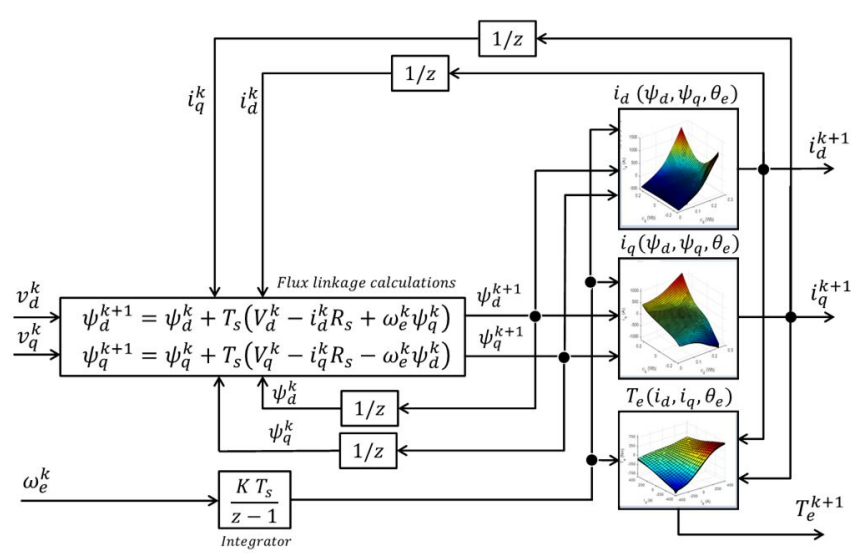

Fig. 2. The FEA-based IPMSM model

Then, the torque $T_{e}^{k+1}$ is predicted by (3), neglecting the cogging torque. Consequently, the prediction model cannot represent the machine behavior accurately.

Therefore, in the proposed approach, the dq-flux linkages and the electromagnetic torque are extracted from the FEA at different currents $\left(i_{d}, i_{q}\right)$ and rotor positions $\left(\theta_{e}\right)$ to include the magnetic saturation, spatial harmonics effects, and the cogging torque in the model. As shown in Fig. 2, for a given voltage, the d- and q- axis flux linkages $\left(\psi_{d}, \psi_{q}\right)$ are calculated using (5). Subsequently, the d- and q-axis currents are obtained from 3D-lookup tables with $\psi_{d}, \psi_{q}$, and $\theta_{e}$ as inputs. Finally, the electromagnetic torque is acquired by (3) also in a form of a 3D-lookup table with $i_{d}, i_{q}$, and $\theta_{e}$ as inputs. This model can be implemented by inversing the solution of currents versus the flux linkages [20], as will be described later.

\section{Voltage Vector Selection and Duty Ratio Regulation}

In the conventional methods, the prediction model is used to get $T_{e}^{k+1}$ and $\psi_{s}^{k+1}$ for each voltage vector represented by (4). After that, a cost function is utilized to evaluate the error between the predicted values and the reference signals to select the optimal voltage vector. The working duration of that voltage vector is then determined based on a control objective, such as minimizing the mean torque error over one control period [15]. However, changing the working duration makes the selected voltage vector non-optimal as it is equivalent to varying the voltage amplitude. As a result, the torque ripple reduction cannot be ensured, especially at low speeds [11]. Therefore, the proposed method simultaneously optimizes the duty ratio with the voltage vector selection.

With the aim of minimizing the rms value of the torque ripple over each control cycle, the duty ratio of the active voltage vectors (i.e., $i \in\{1,2 . ., 6\})$ can be calculated as [15] 


$$
D_{i}^{k}=\frac{2\left(T_{e}^{r e f}-T_{e}^{k}\right)-\Delta T_{e 0}}{2 \Delta T_{e i}-\Delta T_{e 0}}, \quad D_{i}^{k} \in[0,1]
$$

where $\Delta T_{e 0}$ and $\Delta T_{e i}$ are the torque deviations $\left(T_{e}^{k+1}-T_{e}^{k}\right)$ due to the zero and active voltage vectors, respectively, if applied for the whole control cycle. The prediction model can be utilized to determine $T_{e}^{k+1}$ using $V_{i}$ as inputs.

Once the duty ratio is determined for each voltage vector, the values of $T_{e}^{k+1}$ and $\psi_{s}^{k+1}$ are obtained using $D_{i} V_{i}$ as inputs to the prediction model. Then, the cost function $(G)$ is used to evaluate the voltage vectors and their duty ratio to select those of them that achieve the minimum error in the torque and the stator flux amplitude, according to the following expression:

$$
G=\left(\frac{T_{e}^{r e f}-T_{e}^{k+1}}{T_{n}}\right)^{2}+\lambda\left(\frac{\psi_{s}^{r e f}-\psi_{s}^{k+1}}{\psi_{n}}\right)^{2}+f\left(i_{s}^{k+1}\right)
$$

where $T_{n}, \psi_{n}$ are the nominal values of the torque and stator flux, respectively; $\lambda$ is the weighting factor of the stator flux error term; $f\left(i_{s}^{k+1}\right)$ represents the hard constraints to limit the stator current to its peak value $\left(i_{s \text { peak }}\right)$ as follows:

$$
f\left(i_{s}^{k+1}\right)= \begin{cases}\infty & \text { if }\left|i_{s}^{k+1}\right|>i_{\text {s peak }} \\ 0 & \text { if }\left|i_{s}^{k+1}\right| \leq i_{\text {s peak }}\end{cases}
$$

The flow chart shown in Fig. 3 summarizes the algorithm of proposed MP-DTC with the duty ratio regulation.

\section{FEA-BASED IPMSM MODEL}

In this section, the FEA-based model is demonstrated for an $80-\mathrm{kW}$ IPMSM prototype with the specifications listed in Table I. This machine has 48 slots and 4 pole pairs with N42UH magnets. Fig. 4 shows a complete view of the machine and its cross-section.

\section{A. Model Implementation}

First, the FEA is used to determine the dq-flux linkage components and electromagnetic torque at different operating points by varying $i_{d}, i_{q}$, and $\theta_{e}$ in the ranges of $[-400,400] \mathrm{A}$, and $[0,30]$ electrical degrees with steps of $40 \mathrm{~A}$, and 1 degree, respectively. The raw data determined by the FEA is processed using Matlab to generate 3D-lookup tables for the d- and qaxis flux linkage and the torque, as shown in Fig. 5.

In order to reverse the flux-linkage maps, minimum and maximum values of $\psi_{d}$ and $\psi_{q}$ are obtained, and the intervals are subdivided into $n$ divisions $(n=50)$. The inverse solution then can be obtained using the curve fitting tool in Matlab. Fig. 6 depicts the d-and q-axis current maps versus the flux linkages.

Once the inversion of these maps has been accomplished, a validation is carried out by selecting different sets of $i_{d}, i_{q}$, and $\theta_{e}$ and use the original flux linkage maps to compute $\psi_{d}$ and $\psi_{q}$ which are employed to calculate new sets of $i_{d}$ and $i_{q}$ using the inversed maps. Fig. 7 shows the \% error in d- and qaxis currents at $i_{d}=-100 \mathrm{~A}$ and different rotor positions. It can be noticed that the maximum current error is $0.7 \%$. The error at different values of $i_{d}$ were also checked, and they show similar small magnitudes which are not presented for the sake of space.

\section{B. Model verification}

The FEA-based model is implemented in Simulink and verified by experimental results. The IPMSM prototype is drive by a dynamometer, and the no-load test is performed to capture the back-EMF waveforms. Fig. 8 compares the Simulink-, FEA-, and experiment- line-to-line back-EMF at an operating speed of $3000 \mathrm{rpm}$. It can be noticed that the predicted

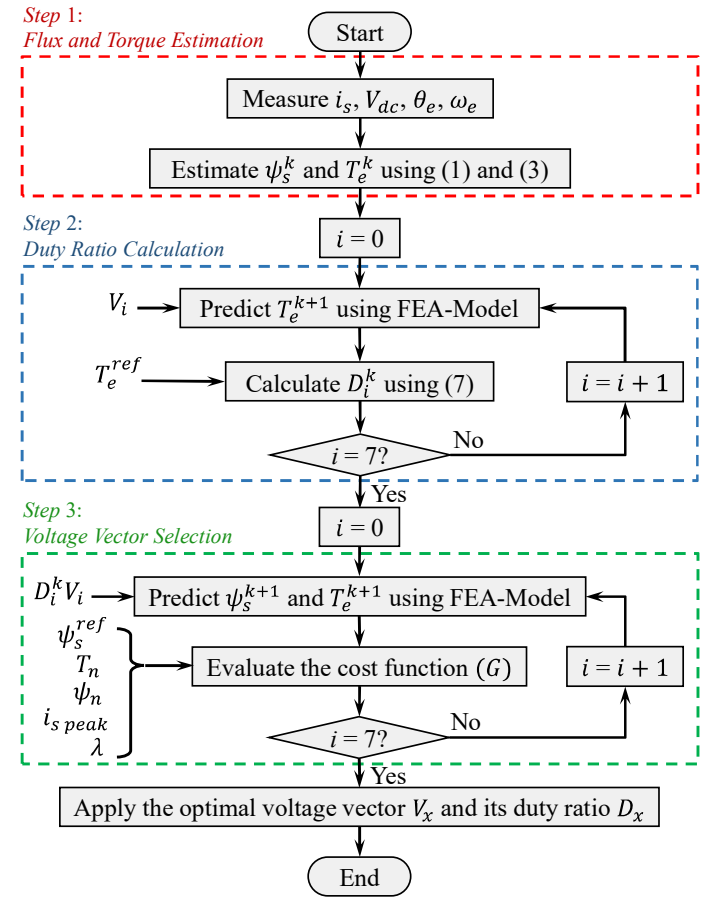

Fig. 3. Flow chart of the proposed MP-DTC with duty ratio regulation

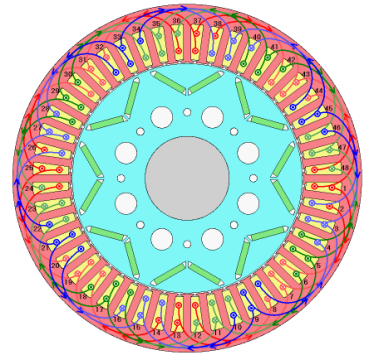

(a)

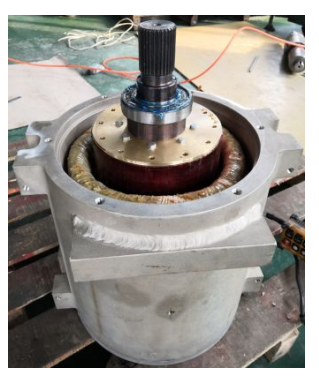

(b)
Fig. 4. The IPMSM prototype: (a) cross-section; (b) complete view

TABLE I. DESIGN PARAMETERS OF IPMSM PROTOTYPE

\begin{tabular}{|ll|ll|}
\hline \hline Electrical parameters & Value & Mechanical parameters & Value \\
\hline Rated power $(\mathrm{kW})$ & 80 & Stator outer diameter $(\mathrm{mm})$ & 290 \\
Rated torque $(\mathrm{Nm})$ & 400 & Rotor outer diameter $(\mathrm{mm})$ & 193 \\
Peak torque $(\mathrm{Nm})$ & 600 & Axial length $(\mathrm{mm})$ & 200 \\
Base speed $(\mathrm{rpm})$ & 3000 & Number of slots & 48 \\
Max. speed (rpm) & 10000 & Number of pole pairs & 4 \\
DC-link voltage (V) & 540 & Number of turns per coil & 12 \\
Peak current (A) & 400 & Air gap length $(\mathrm{mm})$ & 1 \\
\hline \hline
\end{tabular}

back EMF using the Simulink model matches that of the FEA results, but the measured back EMF has a lower ripple because the rotor of the real machine prototype is skewed to reduce the interaction between the magnets and the stator teeth. The rotor skewing is ignored in the simulation to illustrate how the control method can eliminate the torque ripples caused by these interactions.

Besides, to verify the torque prediction at different operating points, the currents $\left(i_{d}=0 \mathrm{~A}, i_{q}=0 \mathrm{~A}\right)$ and $\left(i_{d}=-300 \mathrm{~A}\right.$, $i_{q}=200 \mathrm{~A}$ ) are given to FEA, and the resulting $\mathrm{d}$ - and q-axis flux linkages are then fed to the Simulink model to extract the torque waveforms that are compared in Fig. 9. It can be noticed that the torque waveforms coincide at zero currents, while the difference at the other operating point can be neglected. Thus, it can be stated that the implemented FEA-based provides high accuracy for machine variables prediction. 


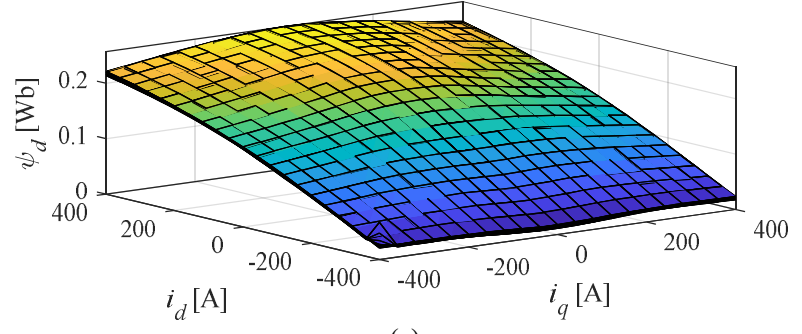

(a)

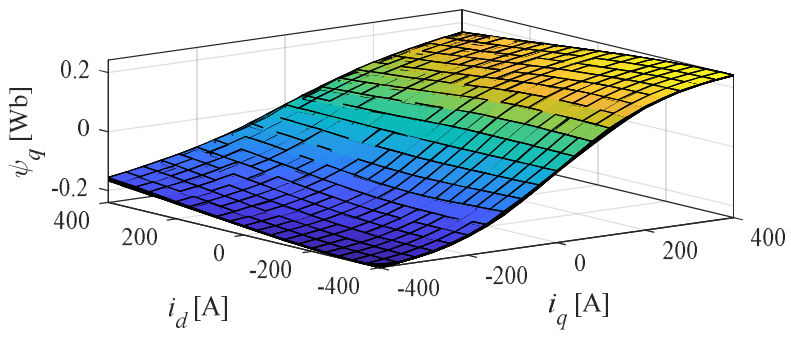

(b)

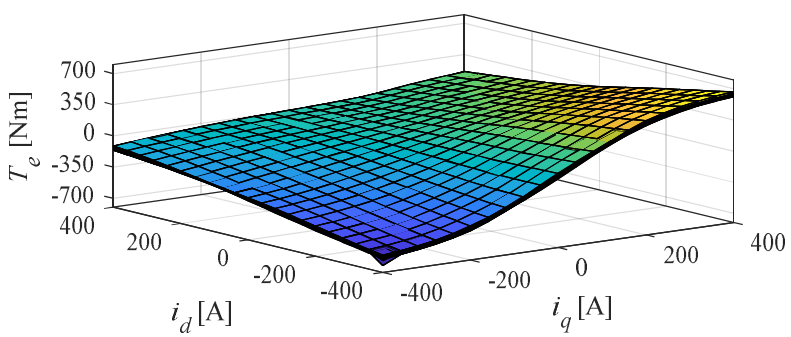

(c)

Fig. 5. Flux linkage and torque maps versus dq-current components

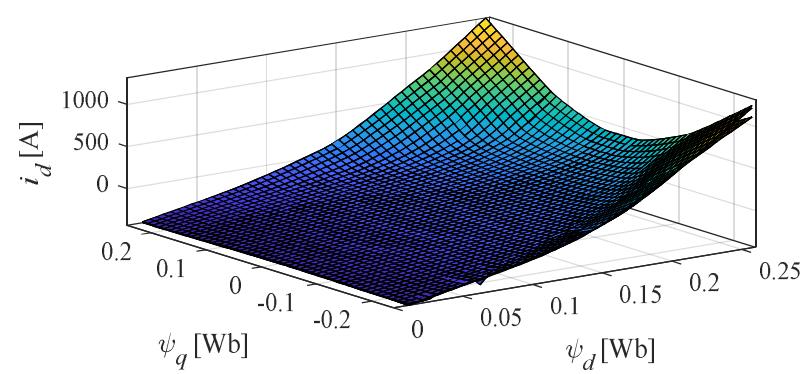

(a)

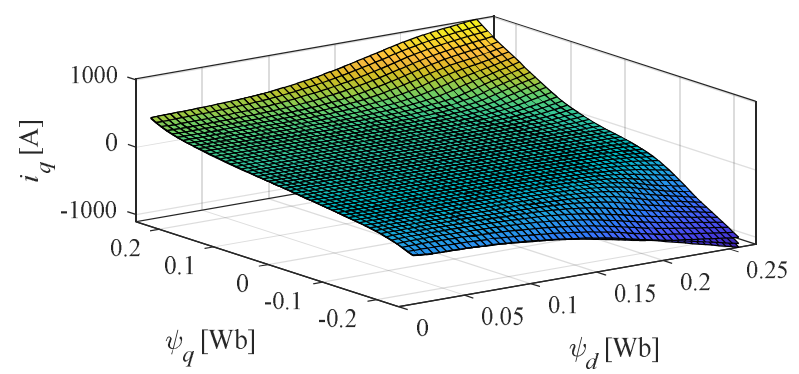

(b)

Fig. 6. Current maps versus d- and q-axis flux linkages

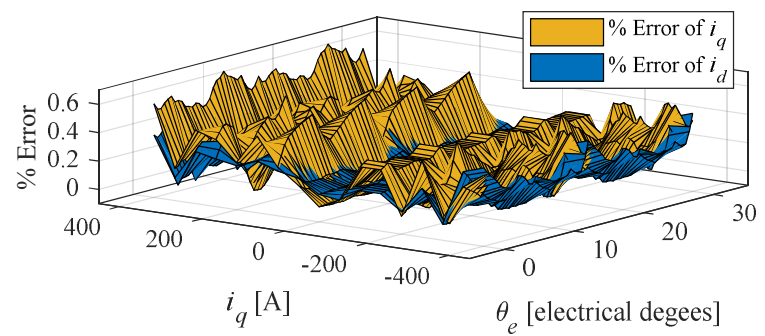

Fig. 7. $\%$ error in $i_{q}$ prediction due to lookup tables inversion at $i_{d}=-100 \mathrm{~A}$ and different rotor positions

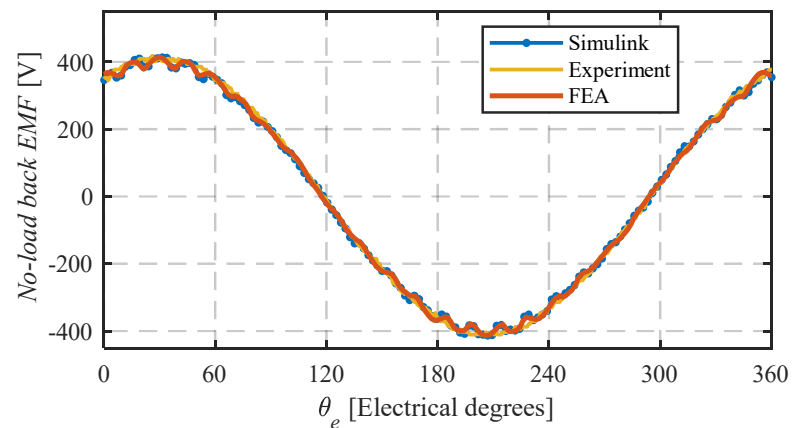

Fig. 8. Simulink-, FEA-, and measured line-to-line back EMF waveforms $3000 \mathrm{rpm}$.

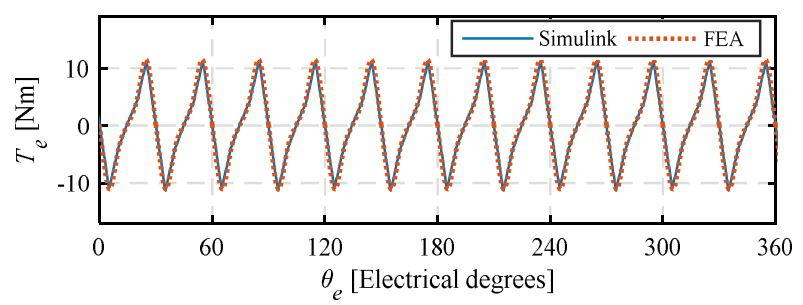

(a)

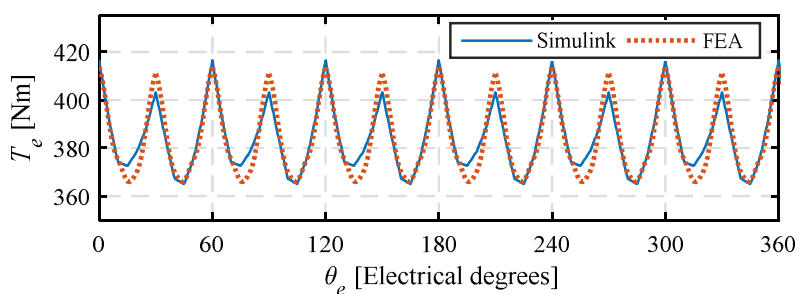

(b)

Fig. 9. Simulink- and FEA-torque waveforms at: (a) $i_{d}=0 \mathrm{~A}, i_{q}=0 \mathrm{~A}$, and (b) $i_{d}=-300 \mathrm{~A}, i_{q}=200 \mathrm{~A}$

\section{Simulation Results}

In this section, the MATLAB/Simulink environment is used to verify the feasibility of the proposed MP-DTC method by comparing its performance with the conventional scheme. The machine under test is driven by a speed source (as a virtual dynamometer) and operates in torque control mode. A twolevel VSI is used to feed that machine, whose switching states are decided by the control algorithm. The stator currents and the rotor position are used as feedback signals for the control algorithm. Park's and Clarke's transformations are utilized to get d- and q-axis stator voltages as inputs of the FEA-based model. The DC supply voltage is maintained at $540 \mathrm{~V}$, and the sampling frequency is decided to be $40 \mathrm{kHz}$. The weighting factor of the cost function (8) is set to 1 to make the torque and stator flux control equally important.

The performance of the proposed MP-DTC without duty ratio regulation is first compared with that of the conventional method (with constant parameters of $\psi_{p m}=0.1837 \mathrm{~Wb}, L_{d}=$ $0.6 \mathrm{mH}$, and $L_{q}=1.33 \mathrm{mH}$ ) to show the benefits of employing the FEA-based model for predictions. Fig. 10 compares the torque, stator flux amplitude, and stator phase current when the machine runs at two different speeds of 500 and $3000 \mathrm{rpm}$ with a demanded torque of 0 and $400 \mathrm{Nm}$, respectively.

As can be noticed in Fig. 10, the proposed MP-DTC reduces the torque ripple considerably for all operating conditions because the FEA-based model can predict the electromagnetic variables of the machine accurately, including the cogging torque and the magnetic saturation impact on the flux linkage. As a result, the harmonics in the stator phase current increases. On the other hand, the conventional method shows 


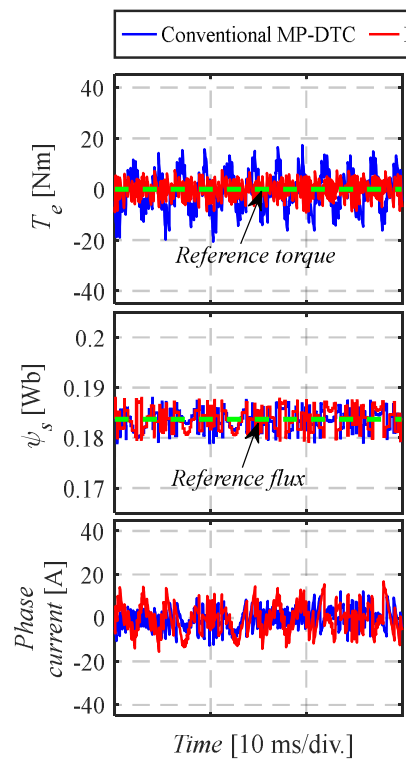

(a)

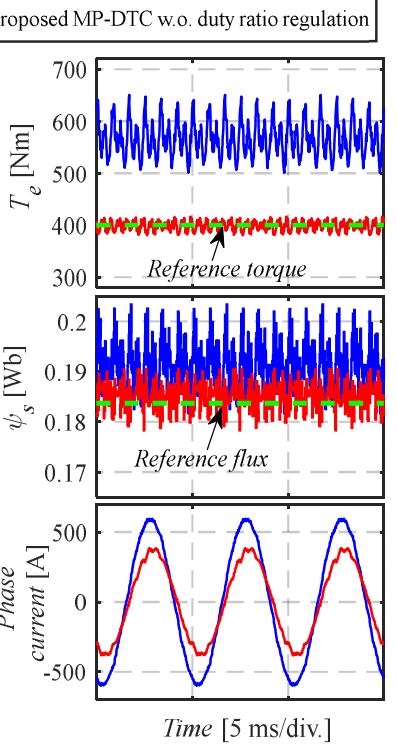

(b)
Fig. 10. Simulation results of estimated torque, stator flux amplitude, and stator phase current at different operating points: (a) $500 \mathrm{rpm}$ and no load; (b) $3000 \mathrm{rpm}$ and $400 \mathrm{Nm}$.

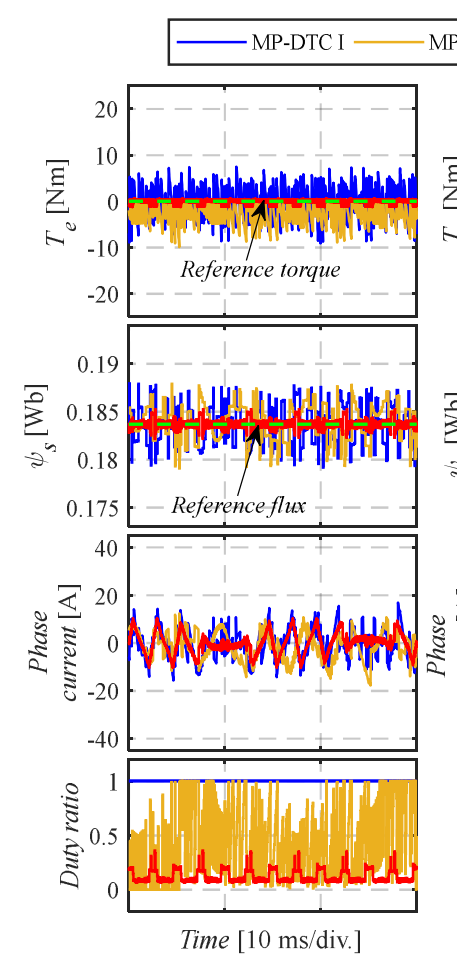

(a)

\section{MP-DTC II — Proposed MP-DTC}
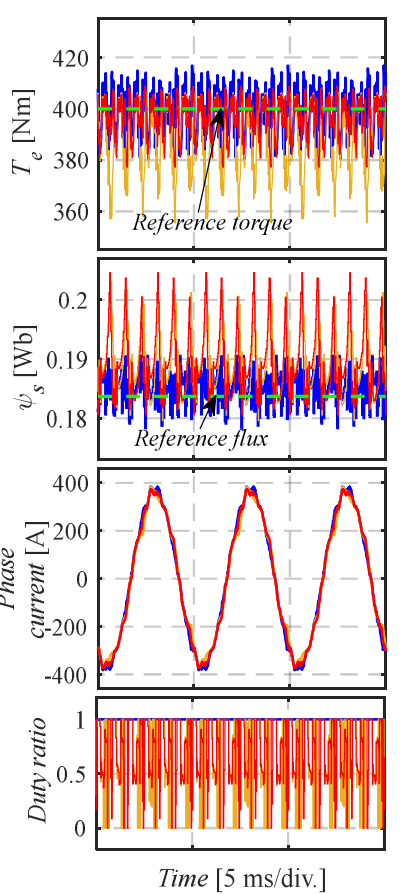

(b)
Fig. 11. Simulation results of estimated torque, stator flux amplitude, stator phase current, and duty ratio at different operating points: (a) $500 \mathrm{rpm}$ and no load; (b) $3000 \mathrm{rpm}$ and $400 \mathrm{Nm}$.

a significant steady-state error in the torque under heavy loading conditions because of the inaccurate current predictions using (6) that neglects the inductance variation with the magnetic saturation.

To verify the effectiveness of optimizing the duty ratio simultaneously with the voltage vector selection, the simulation results of the proposed MP-DTC are compared with those of two other algorithms. 1) MP-DTC without duty ratio regulator. 2) MP-DTC that calculates the duty ratio after the selection of the optimal voltage vector [18]. These two algorithms
TABLE II. QUANTITATIVE EVALUATION OF THE CONTROL METHODS UNDER DIFFERENT SPEEDS AND LOADING CONDITIONS

\begin{tabular}{|c|c|c|c|c|c|c|}
\hline \multirow{2}{*}{ Index } & \multirow{2}{*}{$\begin{array}{l}\text { Speed } \\
(\mathrm{rpm})\end{array}$} & \multirow{2}{*}{$\begin{array}{l}\text { Torque } \\
(\mathrm{Nm})\end{array}$} & \multicolumn{4}{|c|}{ MP-DTC based Control Methods } \\
\hline & & & Conv. & I & II & $\begin{array}{c}\text { Pro- } \\
\text { posed }\end{array}$ \\
\hline \multirow{4}{*}{$\begin{array}{c}T_{\text {ripple }} \\
(\mathrm{Nm})\end{array}$} & \multirow{2}{*}{500} & 0 & 7.15 & 3.09 & 1.92 & 0.41 \\
\hline & & 400 & 33.58 & 5.42 & 3.63 & 0.88 \\
\hline & \multirow{2}{*}{3000} & 0 & 6.97 & 5.11 & 5.16 & 4.29 \\
\hline & & 400 & 32.36 & 7.87 & 13.67 & 7.21 \\
\hline \multirow{4}{*}{$\begin{array}{c}T_{\text {sse }} \\
(\mathrm{Nm})\end{array}$} & \multirow{2}{*}{500} & 0 & 0.86 & 0.15 & 2.44 & 0.06 \\
\hline & & 400 & 166.2 & 0.32 & 3.81 & 0.08 \\
\hline & \multirow{2}{*}{3000} & 0 & 2.31 & 2.37 & 3.30 & 2.01 \\
\hline & & 400 & 169.3 & 3.19 & 13.87 & 4.37 \\
\hline \multirow{4}{*}{$\begin{array}{l}\psi_{\text {ripple }} \\
(\mathrm{mWb})\end{array}$} & \multirow{2}{*}{500} & 0 & 1.95 & 2.14 & 1.91 & 0.51 \\
\hline & & 400 & 4.72 & 2.51 & 2.93 & 0.96 \\
\hline & \multirow{2}{*}{3000} & 0 & 2.26 & 2.32 & 2.34 & 2.02 \\
\hline & & 400 & 4.34 & 3.05 & 5.97 & 5.70 \\
\hline
\end{tabular}

will respectively be designated as MP-DTC I and MP-DTC II for convenience. Fig. 11 compares the torque, stator flux amplitude, stator phase current, and duty ratio when the machine runs at the same operating points mentioned before.

At low speed (i.e., $500 \mathrm{rpm}$ ), as shown in Fig. 11(a), the MP-DTC II achieved less torque ripple than MP-DTC I, but it causes a higher steady-state torque error. The proposed MPDTC exhibits the best steady-state behavior in terms of the torque ripple, steady-state torque error, and flux ripple.

It can be seen in Fig. 11(b) that the proposed MP-DTC achieved the lowest torque ripple at high speed (i.e., 3000 $\mathrm{rpm}$ ), while it increases the flux ripple because the duty ratio regulation gives higher priority for torque ripple minimization. Also, the MP-DTC II deteriorates the overall steady-state performance because the cost function optimization considers applying the voltage vector for the whole control cycle. Thus, changing the duty ratio after the optimization process cannot ensure that the applied voltage vector is optimal.

Table II gives a quantitative evaluation for the control methods in terms of the steady-state torque error, the toque ripple, and the stator flux ripple. The steady-state torque error is detected by comparing the reference torque with the average value of the developed torque, while the ripple is calculated by

$$
y_{\text {ripple }}=\sqrt{\frac{1}{m} \sum_{k=1}^{m}\left(y(k)-y_{a v}\right)^{2}}
$$

where $y$ can be the torque or the stator flux amplitude, $y(k)$ is the instantaneous value, $y_{a v}$ is the average value, and $m$ is the number of samples.

According to Table II, the MP-DTC methods that employ the FEA-based model prediction (i.e., I, II, and proposed) improve the steady-state performance remarkably compared with the conventional scheme, especially under heavy loading conditions. Minimum reductions of $58 \%, 91 \%$, and $29 \%$ are achieved for the torque ripple, steady-state torque error, and flux ripple, respectively, at full load. Among these methods, the proposed MP-DTC exhibits the lowest torque ripple, steady-state torque error, and flux ripple by an average of $77 \%$, $67 \%$, and $68 \%$, respectively, at low speed (i.e., $500 \mathrm{rpm}$ ). This steady-state performance improvement becomes insignificant compared with MP-DTC I with the speed increase, which implies that the duty ratio regulation is more effective at low speeds. Also, it can be noticed that MP-DTC II degrades steady-state performance. These simulation results prove the necessity of employing an accurate prediction model and optimizing both the voltage vector selection and its duty ratio 
simultaneously to improve the torque control performance of PMSM drives, especially at low speeds and heavy loads.

\section{CONCLUSION}

Because the model predictive-based direct torque control technique requires high accuracy for the implemented machine model, this paper proposes utilizing the FEA-based modeling approach for predicting the machine variables. The FEA-based model is implemented in Matlab/Simulink and verified by both FEA results and experiments. The proposed MP-DTC achieved effective torque ripple suppression and eliminated the steady-state torque ripple with an average of $58 \%$ and $90 \%$, respectively, compared with the conventional method that uses the constant-parameters model. Also, this paper investigated the MP-DTC with the duty ratio regulation. The optimization of the duty ratio is essential to be carried out simultaneously with the voltage vector selection to avoid steady-state performance degradation. Moreover, the duty ratio regulation is more beneficial for torque ripple mitigation at low speeds compared with that at high speeds. The practical implementation of the proposed method will be presented in future work.

\section{REFERENCES}

[1] H. Kim, Y. Lee, S. Sul, J. Yu, and J. Oh, "Online MTPA Control of IPMSM Based on Robust Numerical Optimization Technique," IEEE Transactions on Industry Applications, vol. 55, no. 4, pp. 3736-3746, 2019.

[2] S. Li, B. Sarlioglu, S. Jurkovic, N. R. Patel, and P. Savagian, "Analysis of Temperature Effects on Performance of Interior Permanent Magnet Machines for High Variable Temperature Applications," IEEE Transactions on Industry Applications, vol. 53, no. 5, pp. 4923-4933, 2017.

[3] G. Liu, F. Zhai, Q. Chen, and G. Xu, "Torque Pulsation Reduction in Fractional-Slot Concentrated-Windings IPM Motors by Lowering SubHarmonics," IEEE Transactions on Energy Conversion, vol. 34, no. 4, pp. 2084-2095, 2019.

[4] C. Lai, G. Feng, K. Mukherjee, V. Loukanov, and N. C. Kar, "Torque Ripple Modeling and Minimization for Interior PMSM Considering Magnetic Saturation," IEEE Transactions on Power Electronics, vol. 33, no. 3, pp. 2417-2429, 2018.

[5] Z. Q. Zhu, Y. Liu, and D. Howe, "Minimizing the Influence of Cogging Torque on Vibration of PM Brushless Machines by Direct Torque Control," IEEE Transactions on Magnetics, vol. 42, no. 10, pp. 3512 $3514,2006$.

[6] R. Tanabe and K. Akatsu, "Direct torque control of permanent magnet synchronous motor using real-time simulator with FEA based motor model," in 2015 17th European Conference on Power Electronics and Applications (EPE'15 ECCE-Europe), 8-10 Sept. 2015 2015, pp. 1-8.

[7] L. Zhong, M. F. Rahman, W. Y. Hu, K. W. Lim, and M. A. Rahman, "A direct torque controller for permanent magnet synchronous motor drives," IEEE Transactions on Energy Conversion, vol. 14, no. 3, pp. 637-642, 1999
[8] N. Nakao and K. Akatsu, "Suppressing Pulsating Torques: Torque Ripple Control for Synchronous Motors," IEEE Industry Applications Magazine, vol. 20, no. 6, pp. 33-44, 2014.

[9] F. Niu, B. Wang, A. S. Babel, K. Li, and E. G. Strangas, "Comparative Evaluation of Direct Torque Control Strategies for Permanent Magnet Synchronous Machines," IEEE Transactions on Power Electronics, vol. 31, no. 2, pp. 1408-1424, 2016.

[10] X. Zhang and B. Hou, "Double Vectors Model Predictive Torque Control Without Weighting Factor Based on Voltage Tracking Error," IEEE Transactions on Power Electronics, vol. 33, no. 3, pp. 2368-2380, 2018.

[11] Y. Zhang and H. Yang, "Model Predictive Torque Control of Induction Motor Drives With Optimal Duty Cycle Control," IEEE Transactions on Power Electronics, vol. 29, no. 12, pp. 6593-6603, 2014.

[12] Z. Zhou, C. Xia, T. Shi, and Q. Geng, "Model Predictive Direct DutyCycle Control for PMSM Drive Systems with Variable Control-Set," IEEE Transactions on Industrial Electronics, pp. 1-6, 2020.

[13] M. Abdelrahem, H. Eldeeb, C. Hackl, R. Kennel, and J. Rodriguez, "Computationally Efficient Predictive Direct Torque Control Strategy for PMSGs without Weighting Factors," in PCIM Europe 2018; International Exhibition and Conference for Power Electronics, Intelligent Motion, Renewable Energy and Energy Management, 5-7 June 2018 2018, pp. 1-6.

[14] Y. Wang et al., "Fast Response Model Predictive Torque and Flux Control With Low Calculation Effort for PMSMs," IEEE Transactions on Industrial Informatics, vol. 15, no. 10, pp. 5531-5540, 2019.

[15] F. Niu et al., "A Simple and Practical Duty Cycle Modulated Direct Torque Control for Permanent Magnet Synchronous Motors," IEEE Transactions on Power Electronics, vol. 34, no. 2, pp. 1572-1579, 2019.

[16] F. Niu, K. Li, and Y. Wang, "Direct Torque Control for PermanentMagnet Synchronous Machines Based on Duty Ratio Modulation," IEEE Transactions on Industrial Electronics, vol. 62, no. 10, pp. 6160$6170,2015$.

[17] O. Sandre-Hernandez, J. Rangel-Magdaleno, and R. Morales-Caporal, "A Comparison on Finite-Set Model Predictive Torque Control Schemes for PMSMs," IEEE Transactions on Power Electronics, vol. 33 , no. 10 , pp. $8838-8847$.

[18] S. Lv and H. Lin, "Model Predictive Direct Torque Control for PMSM with Duty Cycle Optimization," in 2015 Fifth International Conference on Instrumentation and Measurement, Computer, Communication and Control (IMCCC), 18-20 Sept. 2015 2015, pp. 866-871.

[19] H. Kaimori, N. Nakao, T. Sakaue, and K. Akatsu, "Behavior modeling of permanent magnet synchronous motors using flux linkages for coupling with circuit simulation," in 2014 International Conference on Electrical Machines (ICEM), 2-5 Sept. 2014 2014, pp. 2695-2701.

[20] X. Chen, J. Wang, B. Sen, P. Lazari, and T. Sun, "A High-Fidelity and Computationally Efficient Model for Interior Permanent-Magnet Machines Considering the Magnetic Saturation, Spatial Harmonics, and Iron Loss Effect," IEEE Transactions on Industrial Electronics, vol. 62, no. 7, pp. 4044-4055, 2015.

[21] A. Nasr, C. Gu, S. Bozhko, and C. Gerada, "Performance Enhancement of Direct Torque-Controlled Permanent Magnet Synchronous Motor with a Flexible Switching Table," Energies, vol. 13, no. 8, p. 1907, 2020 . 